DOI 10.37882/2500-3682.2021.03.20

\title{
«ФИКХ МУСУЛЬМАНСКИХ МЕНЬШИНСТВ» \\ И СТЕПЕНЬ ПРИМЕНИМОСТИ КОНЦЕПТА «МУСУЛЬМАНСКИЕ МЕНЬШИНСТВА» В ОТНОШЕНИИ МУСУЛЬМАН РОССИЙСКОЙ ФЕДЕРАЦИИ
}

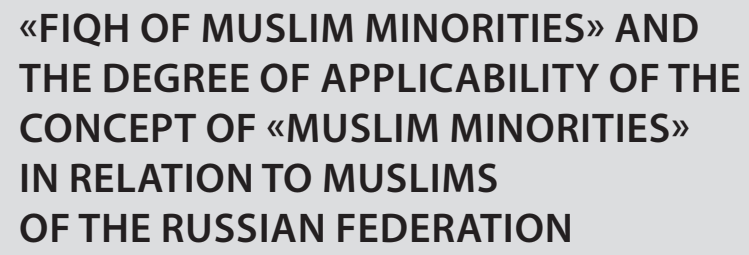

"FIQH OF MUSLIM MINORITIES» AND THE DEGREE OF APPLICABILITY OF THE CONCEPT OF «MUSLIM MINORITIES» IN RELATION TO MUSLIMS OF THE RUSSIAN FEDERATION

R. Tagirov

Summary: The article deals with the preconditions for the emergence of one of the modern directions of figh (Islamic law) - fiqh of Muslim minorities, its main characteristic features and the content of this concept. The focus is on the strategic challenges facing the figh of minorities and the role of the European Council for Fatwa and Research in the development of this direction. The article also analyzes the main criteria for judging the degree of applicability of the concept of «Muslim minorities» in relation to Muslims of Russia. In addition, the article touches on the role of this trend in the formation of Muslim identity, primarily in Europe, and if we analyze the situation in the community Muslims of Russia - the potential role of the figh of minorities in the formation of Russian Muslim identity. In turn, this allows us to name promising areas of research on the phenomenon of figh of minorities in the future.

Keywords: muslim minorities, figh of Muslim minorities, Muslim community, religious identity, European Council for Fatwa and Research, issuing fatwas, Bolgar Islamic Academy.

\section{Введение}

И сследования концепции «фикха мусульманских меньшинств», на наш взгляд, актуальны не только с теоретической точки зрения - возникновение терминов, их значение, обоснованность с точки зрения знатоков исламского фикха и так далее. Не менее важна и практическая сторона: поскольку фикх мусульманских меньшинств имеет свои особенности, это скорее «фикх исключений» чем «фикх правил», и поэтому отнесение той или иной группы (сообщества) мусульман к категории религиозных меньшинств влечёт за собой обоснованность применения методологии, складывающейся в данном направлении фикха.

\section{1. Возникновение и характерные черты коншепции «фикх мусульманских меньшинств»}

По мнению одного из российских исследователей
Тагиров Руслан Гуфурович

Соискатель, Казанский (Приволжский)

Федеральный университет ruslanhajj@gmail.com

Аннотация: В статье рассматриваются предпосылки возникновения одного из современных направлений фикха (исламского права) - фикха мусульманских меньшинств, его основные характерные черты и содержание данной концепции. Основное внимание уделяется стратегическим задачам, стоящим перед фикхом меньшинств, и роли Европейского совета по фетвам и исследованиям в развитии данного направления. Также анализируются основные критерии, позволяющие судить о степени применимости концепта «мусульманские меньшинства» в отношении российских мусульман. Кроме того, в статье затрагивается вопрос о роли данного направления в формировании мусульманской идентичности, прежде всего в Европе, а при анализе ситуации в сообществе российских мусульман - потенциальную роль фикха меньшинств в формировании российской мусульманской идентичности. В свою очередь, это позволяет назвать ряд перспективных направлений исследований феномена фикха меньшинств в будущем.

Ключевые слова: мусульманские меньшинства, фикх мусульманских меньшинств, мусульманское сообщество, религиозная идентичность, Европейский совет по фетвам, фетвотворчество, Болгарская исламская академия.

фикха мусульманских меньшинств Руслана Курбанова, одним из первых термин «фикх мусульманских меньшинств» использовал в 1994 г. Таха Джабир аль-'Альвани (1935-2016) и его называют одним из тех, кто стоял у истоков возникновения данной концепции в 90-х годах XX века [1]. Однако следует отметить, что идея необходимости выработки особого подхода для мусульман, живущих в немусульманском окружении, возникла несколько раньше. Так, шейх Юсуф аль-Карадави (р. 1926), участвуя в программе «аш-Шари'а уа аль-хайат» на канале «аль-Джазира» говорит: «Я помню, как около двадиати пяти лет назад, когда вышла моя книга "Немусульмане в мусульманском обществе", со мной встретился один из братьев, интересующийся проблемами ислама и мусульман. Он сказал мне: "Мы хотим другую книгу. Да, и эта книга важна, но мы хотим книгу, которую считаем ешё более важной", и когда я спросил его: "И что же это [за книга]?", он ответил: "Книга "Мусульмане в немусуль- 
манском обществе". Это тот вид книг, в котором мы нуждаемся". И действительно, в наше время возникло множество новых вопросов и проблем как внутри мусульманского сообщества, так и вне его. И если мы внутри мусульманского сообщества испытываем трудности с этими новыми проблемами и грандиозными изменениями, то что же можно сказать о тех [мусульманах], кто живёт вне мусульманского сообщества?» [2].

Поскольку передача состоялась 14 сентября 1996 г., то можно сказать что идея о необходимости выработки особого подхода в фикхе для мусульманских меньшинств возникла несколько раньше, чем она была озвучена аль-'Альвани. В пользу данного утверждения свидетельствует тот факт, что д-р Юсуф аль-Карадави посвятил данной концепции одну из своих работ, которая так и называется - «Фи фикх аль-акаллийат» («О фикхе меньшинств»), изданную в 1968 г. Таким образом, обоснование концепции и её название появляются уже в конце 60-х годов XX века.

Что касается трактовки самого понятия «фикх меньшинств», то аль-'Альвани - исходя из понимания термина «меньшинство» как «группа или слои населения, относящиеся к расе, языку или религии, отличной от расы, языка или религии большинства в государстве» [3, 2], даёт следующее определение: «Фикх меньшинств - это разновидность фикха, учитывающая связь шариатской нормы с обстоятельствами определённой группы и местности, в которой она проживает. Таким образом, это фикх ограниченной группы, находящейся в особой ситуации, подходящий только ей и не подходящий другой» $[3,3]$.

По мнению аль-Карадави, «фикх меньшинств» представляет собой «фикх живущих на чужбине» или «мусульман в немусульманском сообществе» [4, 13], при этом с точки зрения территории проживания он разделяет всех мусульман на две основные категории - проживающих в мусульманских странах, и проживающих вдали от мусульманских сообществ или за пределами исламского мира. Эта вторая категория (которую он относит к меньшинству), подразделятся на две подкатегории: коренные жители страны, принявшие ислам уже давно, но являющиеся относительным меньшинством по сравнению со своими согражданами-немусульманами; и приехавшие из мусульманских стран в немусульманские на работу или учёбу, либо эмигрировал туда на других законных основаниях, кто-то из них получил гражданство, а вместе с ним гражданские, избирательные и иные права [4, 16-17].

Анализируя вышеприведённые определения фикха мусульманских меньшинств, хочется отметить ряд принципиальных для нашего исследования моментов:

- это фикх мусульман в немусульманском сообществе;

- это фикх ограниченной группы, находящейся в особой ситуации, подходящий только ей и не под- ходящий другой;

- к «мусульманским меньшинствам» относятся мусульмане, проживающие в меньшинстве в немусульманских странах, как коренные жители, так и эмигрировавшие либо временно проживающие там на каком-либо законном основании.

Следует отметить, что в исламском мире с использованием термина «мусульманские меньшинства» согласны далеко не все. Так, в частности, в постановлении № 151 (9/XVI) Международной академии исламского фикха (г. Джидда, учреждена под эгидой ОИК в 1981 г.) говорится: «Следует избегать использования в отношении исламского присутствия за пределами исламского мира названий "меньшинства" или "диаспоры", поскольку эти названия являются юридическими терминами, не учитывающими истинной сути присутствия ислама [в этих регионах], для которого характерны всеобщность, самобытность, стабильность и мирное сосуществование с другими сообществами. Наиболее подходящими для этого названиями могут быть такие как "мусульмане на Западе" или "мусульмане за пределами исламского мира"» $[5,711]$. Также одним из противников концепции фикха меньшинств был и известный исламский учёный д-р Мухаммад Са'ид Рамадан аль-Бути (1929-2013), в одной из своих пятничных проповедей назвавший фикх меньшинств «лживой выдумкой» [6], и «эти фетвы, внешне выглядящие исламскими, на самом деле служат иелям Запада и направлены на раздробление исламской уммы» [7].

Что касается стратегических задач, стоящих перед фикхом мусульманских меньшинств, то о них можно судить по основным проблемам, послужившим толчком к возникновению и развитию данного направления. Первой из таких проблем является широкий спектр нерешённых вопросов частной, общественной и политической жизни в новых для мусульман условиях $[4,26-$ 28], вторая заключается в отсутствии у мусульманских меньшинств единой инстанции, которая, будучи хорошо знакома с жизнью в этих странах, отвечала бы на многочисленные вопросы [2]. В качестве третьей называются методологические проблемы, не позволяющие в полной мере использовать классический фикх для решения возникающих вопросов [3, 10-11]. Можно предположить, что эти основные проблемы включают в себя значительное количество второстепенных вопросов различного характера, решением которых и занимается фикх меньшинств.

- Таким образом, возвращаясь к вопросу о стратегических задачах фикха меньшинств, можно сформулировать их следующим образом:

- Создание единой инстанции, которая занималась бы исследованием проблем мусульманских меньшинств и вынесением для них богословских заключений - фетв (арабск. аль-фратва).

- Выработка особой методологии фикха мусульманских меньшинств. 
- Решение широкого спектра вопросов частной, общественной и политической жизни в новых для мусульман условиях.

Поскольку концепция фикха меньшинств начала складываться несколько десятилетий назад, то определённые шаги в решении этих задач на сегодня уже сделаны и одним из важнейших можно назвать создание Европейского совета по фетвам и исследованиям (учреждён в 1997 г., штаб-квартира в г. Дублин, Ирландия), первым председателем был избран Юсуф аль-Карадави. В качестве целей Совета озвучиваются такие как: сближение между исламскими учёными на европейском пространстве и выработка общих решений; издание коллективных фетв, удовлетворяющих потребности мусульман в Европе; проведение и публикация шариатских исследований по проблемам религиозной жизни на европейском пространстве; наставление мусульман Европы через распространение основополагающих исламских понятий и издание фетв. Также на сайте Совета перечисляются средства достижения поставленных целей, источники и критерии вынесения фетв, вкратце оговаривается методология, на которую опирается Совет при вынесении своих фетв и постановлений [8].

Анализируя концепцию «фикх мусульманских меньшинств» и стоящие перед ним (фикхом меньшинств) стратегические задачи, а также принимая во внимание цели, озвученные Европейским советом по фетвам и исследованиям, можно сказать, что данная организация по праву может считаться одной из высших инстанций, созданных и функционирующих в интересах мусульманских меньшинств, по крайней мере в Европе. Соответственно, позиция Совета и его методология могут считаться отражением методологии фикха мусульманских меньшинств в целом, а его фетвы, как минимум, служить прецедентом для решения аналогичных проблем для меньшинств в других регионах в схожих ситуациях.

Создание Европейского совета по фетвам и исследованиям, на наш взгляд, было обусловлено необходимостью выработать методологию вынесения фетв в контексте глубокого понимания жизни в Европе, понимания проблем европейцев, их логики в повседневной жизни, а также с учётом географических и культурных особенностей и традиций. Таким образом, перед современными знатоками фикха встала задача аналогичная той, с которой столкнулись исламские учёные и богословы на самом раннем этапе становления фикха. То есть: подобно тому, как принятие во внимание обычаев и традиций жизни на Аравийском полуострове и жизни в Ираке сыграло свою роль в формировании фикха Хиджаза (школы ахль-хадис) и иракской школы (школы ахль-ра'й), современным знатокам фикха нужно было выносить новые фетвы, учитывающие обстоятельства жизни в Европе. В качестве основания для этого может служить то, что обычаи и традиции (не противоречащие прямым и категоричным доказательствам), должны учитываться при выведении шариатских норм. Например, в фикхе существует такой основополагающий принцип как «Традиция устанавливается в качестве нормы» [9, с. 28], из которого в свою очередь вытекает целый ряд других, и в частности «Не следует отвергать изменение предписаний с изменением времён» [9, с. 28].

\section{2. Степень обоснованности применения коншепта «мусульманские меньшинства» в отношении российских мусульман}

Прежде чем приступить к вопросу о том, насколько возможно применение концепта «мусульманские меньшинства» в отношении мусульман Российской Федерации, отметим, что говоря о мусульманских сообществах мы обобщаем и абстрагируем, поскольку само понятие «мусульманское сообщество» довольно условно и точно установить границы такого сообщества зачастую оказывается сложно.

Итак, что касается применения данного концепта в отношении всех мусульман в Российской Федерации, следует отметить, то на наш взгляд это будет не совсем корректным в силу ряда причин:

1. Ислам на территорию нашей страны пришёл во времена сподвижников пророка Мухаммада, примерно в 642 г., а в г. Дербент (Дагестан) находится старейшая в Российской Федерации и сохранившаяся до наших дней соборная мечеть, дата постройки 733-734 гг. [10, 65-66].

2. Официальное принятие ислама Волжской Болгарией в 922 г., при этом Ибн Фадлан в своих путевых записках говорит о том, что ислам на этих территориях уже практиковался и, по-видимому, пришёл с купцами и проповедниками [10, 550-553; $11,12-18 ; 12,129-130]$.

3. Золотая Орда, куда входили обширные территории современной Российской Федерации, приняла ислам на государственном уровне уже в начале 20-х годов XIV века при хане Узбеке [11, 19-20; 12, 130-133].

4. Ислам в качестве государственной религии сохранился на территории нашей страны и после распада Золотой Орды - Большая Орда, Астраханское, Казанское, Крымское ханства, Ногайская Орда [11, 20-21; 12, 125-127 и 130-133].

5. Ислам сохранил своё присутствие на этих территориях с момента своего распространения, и, таким образом, в некоторых регионах нашей страны имеет более чем тысячелетнюю историю [11, 22-35 и 35-43].

6. Арабское письмо, получившее распространение на территории нашей страны с приходом ислама [10, 560-561], использовалось вплоть до 30-х го- 
дов XX века, да и поныне оно используется в Российской Федерации в сфере исламского духовного образования.

7. В регионах традиционного распространения ислама в нашей стране мусульман нельзя назвать меньшинством, поскольку где-то мусульмане составляют значительную или даже большую часть населения (например Башкортостан, Дагестан, Ингушетия, Кабардино-Балкария, Карачаево-Черкесия, Крым, Татарстан или Чечня).

8. Народы, традиционно считающиеся последователями ислама, являются коренными для нашей страны и имеют свои давние связанные с исламом культуру, традиции и обычаи, среди них имели распространение, а где-то и сохраняются суфийские духовные практики [12, 126, 311-312].

9. Мусульмане нашей страны традиционно являются последователями ханафитского или шафиитского мазхаба, со своими образовательными центрами и традициями образования, духовными управлениями $[10,29]$ или инстанциями, куда обращались за фетвами, существовал у мусульман на территории нашей страны и свой институт кадиев (шариатских судей) [10, 65-66 и 561-562; 11, 17-21, 59-63 и 122-124; 12, 126-130]. Такая ситуация сохраняется в целом и поныне.

Обобщая вышеизложенное, отметим, что ислам на территории Российской Федерации имеет древнюю историю и сохраняет влияние и поныне, и отнести всех мусульман к некоей слабой малочисленной общности в иноверческом окружении будет не совсем корректно. В пользу данного суждения может свидетельствовать то, что в местах исторического компактного проживания мусульмане представляют собой уже сложившуюся общность со своими религиозными институтами. Кроме того, ислам в Российской Федерации имеет свои характерные особенности, что стало следствием проживания мусульман в многонациональном и многоконфессиональном окружении, и вполне возможно, что это формирует особую идентичность ислама на Евразийском пространстве. Также следует отметить, что правильнее будет проводить аналогии не со странами Западной Европы или Северной Америки, а приводить в пример Индию или Китай, поскольку в каждой из этих стран проживает до 100 миллионов мусульман, и вместе с этим они представляют собой относительное «меньшинство», хоть и многомиллионное.

Принимая во внимание точку зрения аль-Карадави - проживание в стране с преобладающим немусульманским населением и не относящейся к исламскому миру (пусть и в абстрактном его понимании), а также учитывая рассмотренные выше причины, по которым не совсем корректно относить всех мусульман России к религиозным меньшинствам, можно сказать, что концепт «мусульманские меньшинства» может соотноситься с некоторыми сообществами мусульман в нашей стране:

а) новообращённых мусульман;

б) группами, проживающими в меньшинстве вне территорий исторического распространения ислама.

Здесь мы вполне можем допустить влияние различных методологий, в том числе и фикха мусульманских меньшинств, это обусловлено тем, что первые исторически не соотносят себя ни с какой религиозной традицией в исламе, а вторые, если окажутся оторванными от своих исторических корней или национальных сообществ, также могут принять ту или иную трактовку фикха и обращаться в те инстанции, которые им будут доступны или считаются ими более авторитетными. В отношении именно этих сообществ понятие «мусульманские меньшинства» может быть использовано, тем более что одним из факторов, способствующих обращению к фикху мусульманских меньшинств данными категориями, может служить общность проблематики, а также наличие в фикхе меньшинств решений, которые могут дать ответ на возникающие в этой среде вопросы религиозной жизни.

\section{Зак^ючение}

Фикх мусульманских меньшинств, с учётом рассмотренных определений, это совокупность фетв, которую следует рассматривать в динамике изменения обстоятельств и времени, и соответственно, нормы применимые к одной ситуации, могут кардинальным образом отличаться от их применения в другой. Значительную роль в фикхе меньшинств в этой связи играет такой фактор как обычаи и традиции.

С учётом многовековой истории ислама на территории Российской Федерации, следует отметить, что значительная часть мусульман представляет собой уже сложившуюся историческую общность со своими традициями и религиозными институтами. К категории «мусульманских меньшинств» может быть отнесена только ограниченная часть мусульманского сообщества - так называемые новообращённые мусульмане и группы, проживающие в меньшинстве вне территорий исторического распространения ислама.

По аналогии с тем, как фикх меньшинств (по крайней мере в рамках деятельности Европейского совета по фетвам) учитывает особенности жизни мусульман в Европе, можно допустить возникновение со временем такого явления как особые походы в вынесении фетв для российских мусульман. Не исключено, что когда-то этот фактор сыграет свою роль в формировании некой евразийской мусульманской идентичности. Одним из свидетельств в пользу подобных предположений являются попытки создания на базе Болгарской исламской академии площадки для обсуждения и решения насущ- 
ных проблем религиозной жизни мусульманского сообщества России. Одним из вызывающих живой интерес направлений в деятельности проводимого в Академии ежегодного форума развитие фетвотворческих институтов в России и анализ аспектов их деятельности.

Следует отметить, что к персептивным направлени- ям исследования феномена фикха мусульманских меньшинств можно отнести анализ его методологии, факторы, способствующие её распространению. Кроме того, при изучении всего объёма вынесенных постановлений и фетв Европейского совета как одной из важнейших инстанций фикха меньшинств судить о процессах развития и изменения в его методологии.

\section{ЛИТЕРАТУРА}

1. Курбанов Р.В. Фикх мусульманских меньшинств. Мусульманское законодательство в современном немусульманском мире / Издательский дом «Медина» [Электронный ресурс]. Режим доступа: URL http://www.idmedina.ru/books/theology/?4888 (дата обращения 14.02.21).

2. Йусуф аль-Карадави, программа «аш-Шари'а уа аль-хайат», серия «Фикх аль-акаллиййат» / Aljazeera Media Network [Электронный ресурс]. Режим доступа: URL https://www.aljazeera.net/programs/religionandlife/2004/6/4/\%D9\%81\%D9\%82\%D9\%87-\%D8\%A7\%D9\%84\%D8\%A3\%D9\%82\%D9\%84\%D9\%8A \%D8\%A7\%D8\%AA (дата обращения 14.02.21).

3. Таха Джабир аль-'Альвани, статья «Фикх аль-акаллиййат: назрат та'сисиййа» / «Акадимийат Таха аль-'Альвани ли-д-дирасат аль-куранийя» [Электронный ресурс]. Режим доступа: URL https://alwani.org/?p=2288 (дата обращения 15.02.21).

4. ̆усуф аль-Карадави. Фи фикхи аль-акаллиййат аль-муслима. Каир: Дар аш-шурук, 1968. - 207 с.

5. Маджаллят маджма' аль-фикх аль-ислями ад-даули. ад-Даурату ас-садисата 'ашар. № 16/ 4. 2007 г. 729 с.

6. Хутбату-ль-имам аш-шахид аль-Буты. Йусру-д-дин ва укзубат фикхи-ль-акаллиййат / Просветительский сайт «Насим аш-шам» [Электронный ресурс]. Режим доступа: URL https://naseemalsham.com/speeches/view/20010406 (дата обращения 17.02.21).

7. Аль-Буты. «Фатава ислямийя фи мазхариха уа хадима ли-ль-гарб фи хаккыкатиха». Просветительский сайт «Насим аш-шам» [Электронный ресурс]. Режим доступа:URL https://www.naseemalsham.com/persons/muhammad_said_ramadan_al_bouti/subjects/view/58415 (дата 0бращения 17.02.21).

8. Ман нахну (Кто мы?) / Официальный сайт European Council for Fatwa and Research [Электронный ресурс]. Режим доступа: URL https://www.e-cfr. org/\%D9\%85\%D9\%86-\%D9\%86\%D8\%AD\%D9\%86/ (дата обращения 17.02.21).

9. аль-Маджалля (Маджаллят аль-ахкам аль-'адлиййа). Бейрут: аль-Матба'а аль-адабиййа, 1403 г.х. - 260 c.

10. «История татар с древнейших времён» в 7 т., том II: «Волжская Булгария и Великая Степь». - Казань: Изд. РухИЛ, 2006. - 960 c.

11. Мухаметшин Р.М. Ислам в общественной и политической жизни татар и Татарстана в XX веке. - Казань: Татар. Кн. изд-во, 2005. - 246 с.

12. Хайрутдинов Р.Р. Ислам на европейском Востоке: Энциклопедический словарь / Р.Р. Хайрутдинов и другие; под ред. Р.А. Набиева - Казань: Магариф, 2004. - 383 c. - c. 129-130; 